
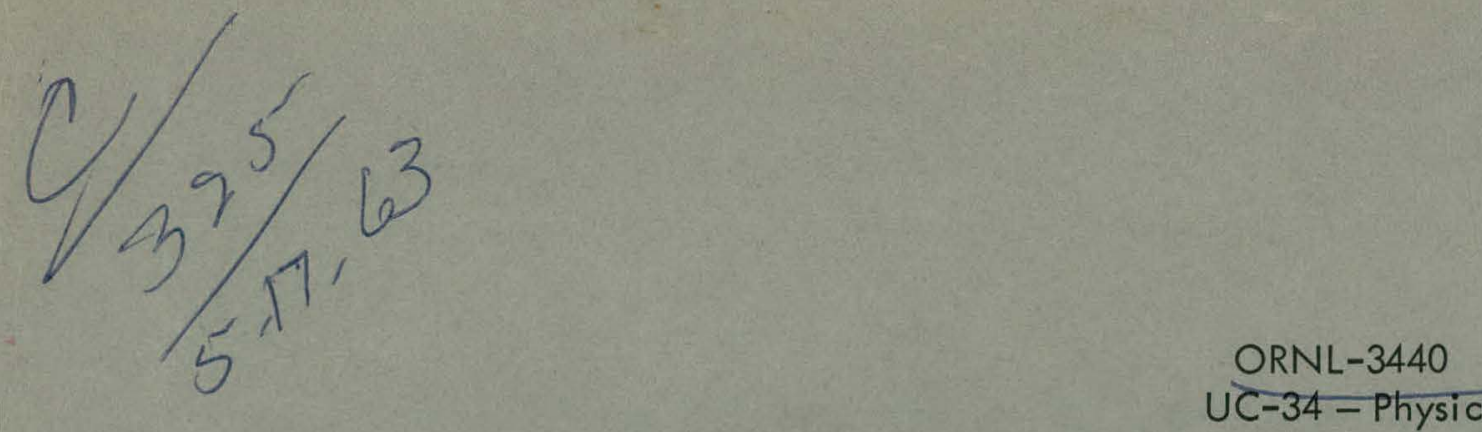

TID-4500 (19th ed., Rev.)

\title{
RECURSION RELATIONS AND SIMPLIFIED \\ EXPRESSIONS FOR THE 6-j SYMBOLS
}

C. D. Zerby

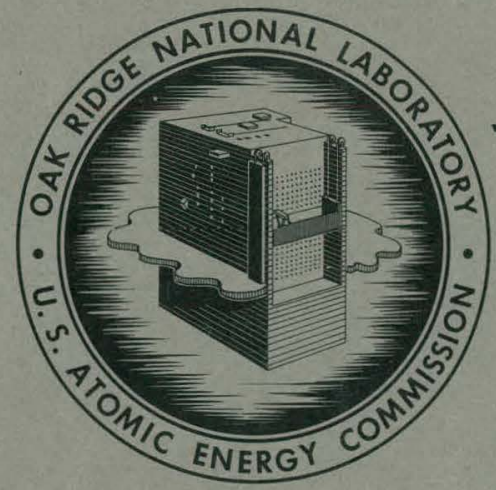

OAK RIDGE NATIONAL LABORATORY

$$
\text { operated by }
$$

UNION CARBIDE CORPORATION

for the

U.S. ATOMIC ENERGY COMMISSION 


\section{DISCLAIMER}

This report was prepared as an account of work sponsored by an agency of the United States Government. Neither the United States Government nor any agency Thereof, nor any of their employees, makes any warranty, express or implied, or assumes any legal liability or responsibility for the accuracy, completeness, or usefulness of any information, apparatus, product, or process disclosed, or represents that its use would not infringe privately owned rights. Reference herein to any specific commercial product, process, or service by trade name, trademark, manufacturer, or otherwise does not necessarily constitute or imply its endorsement, recommendation, or favoring by the United States Government or any agency thereof. The views and opinions of authors expressed herein do not necessarily state or reflect those of the United States Government or any agency thereof. 


\section{DISCLAIMER}

Portions of this document may be illegible in electronic image products. Images are produced from the best available original document. 
Printed in USA. Price: $\$ 0.50$ Available from the

Office of Technical Services

U. S. Department of Commerce

Wushington 25, D. C.

\section{LEGAL NOTICE}

This repart was prepared as an account of Government sponsored work. Neither the United States, nor the Commission, nor any person acting on behalf of the Commission:

A. Makes any warranty or representation, expressed or implied, with respect to the accuracy, completeness, or usefulness of the information contained in this report, or that the use of any information, apparatus, method, or process disclosed in this report may not infringe privately owned rights; or

B. Assumes any liabilities with respect to the use of, or for damages resulting from the use of any information, apparatus, method, or process disclosed in this report.

As used in the above, "person acting on behalf of the Commission" includes any employee or contractor of the Commission, or employee of such contractor, to the extent that such employee or contractor of the Commission, or employee of such contractor prepares, disseminates, or provides access to, any information pursuant to his employment or contract with the Commission, or his employment with such contractor. 
ORNL-3440

Contract No. W-7405-eng-26

Neutron Physics Division

-RECURSION RELATIONS AND SIMPLIFIED EXPRESSIONS FOR THE 6-j SYMBOLS

C. D. Zerby

Date Issued

MAY 161963

OAK RIDGE NATIONAI LABORATORY

Oak Ridge, Tennessee

uper'bled by

UNION CARBIDE CORPORATION

for the

U.S. ATOMIC ENERGY COMMISSION 
THIS PAGE

\section{WAS INTENTIONALLY LEFT BLANK}




\section{Abstract}

It is shown that the 144 symmetry properties of the 6-j symbols which were discovered by Regge can be displayed with a 4 x 4 array which is invariant to the ordering of three of the rows and all columns. The elements of the array are linear combinations of the quantum numbers. In addition, it is shown that a large set of three-term recursion relations exist. The recursion relations are used to deduce simplified expressions for the $6-j$ symbols in special cases. 
The Wigner 6-j symbol, ${ }^{1}$ which is related to the Racah W-coefficient ${ }^{2}$ by

$$
\left\{\begin{array}{lll}
a & b & c \\
d & e & f
\end{array}\right\}=(-1)^{a+b+e+d} w(\text { abed, } c f),
$$

can be represented by the notation

$$
\begin{aligned}
\left\{\begin{array}{lll}
a & b & c \\
d & e & f
\end{array}\right\} & =\left[\begin{array}{llll}
a+b-c & a+e-f & b+d-f & -c+d+e \\
a-e+f & a-b+c & c+d-e & -b+d+f \\
b-d+f & c-d+e & -a+b+c & -a+e+f \\
c+d+e+1 & b+d+f+1 & a+e+f+1 & a+b+c+1
\end{array}\right] \\
& =\left[\begin{array}{llll}
B_{11} & B_{12} & B_{13} & B_{14} \\
B_{21} & B_{22} & B_{23} & B_{24} \\
B_{31} & B_{32} & B_{33} & B_{34} \\
B_{41} & B_{42} & B_{43} & B_{44}
\end{array}\right],
\end{aligned}
$$

where every element $B_{i j}$ is a positive integer or zero.

The advantage of the square array notation is that it efficiently displays the 144 symmetry properties of the 6-j symbol that were discovered by Regge ${ }^{3}$ since it is invariant to the ordering of the four columrs and to the ordering of the first three rows. This notation is similar to that used by Regge ${ }^{4}$ to display the symmetry properties of the $3-j$ symbols. The invariance of the square array can be proved with the help of Racah's formula fo: the W-coefficient modified according to Eq. 1 and expressed in terms of the elements $B_{i, j}$ :

1. E. P. Wigner, "On the Matrices Which Reduce the Kronecker Products of Representations of Simple Reducible Groups," unpublished.

2. G. Racah, Phys. Rev. 62, 438 (1942); Phys. Rev. 63, 367 (1943).

3. T. Regge, Nuovo cimento 11,116 (1959).

4. T. Regge, Nuovo cimento 10, 544 (1958). 


$$
\begin{gathered}
{\left[\begin{array}{cccc}
B_{11} & B_{12} & B_{13} & B_{14} \\
B_{21} & B_{22} & B_{23} & B_{24} \\
B_{31} & B_{32} & B_{33} & B_{34} \\
B_{41} & B_{42} & B_{43} & B_{44}
\end{array}\right]=(-1)^{B_{41}+1}\left[\begin{array}{cccc}
B_{22} ! B_{23} B_{24} ! B_{32} ! B_{33} ! B_{34} ! B_{41} ! \\
B_{11} ! B_{12} ! B_{13} ! B_{14} ! B_{21} ! B_{31} ! B_{42} ! B_{43} ! B_{44} !
\end{array}\right]^{\frac{1}{2}}} \\
X_{0}\left\{\begin{array}{cccc}
B_{11} & B_{12} & B_{13} & B_{14} \\
B_{21} & B_{22} & B_{23} & B_{24} \\
B_{31} & B_{32} & B_{33} & B_{34} \\
B_{41} & B_{42} & B_{43} & B_{44}
\end{array}\right\},
\end{gathered}
$$

where

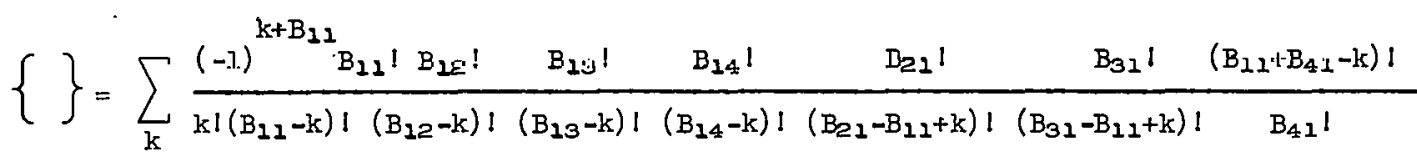

With the aid of the new notation it is possible to display $(144)^{3}$ three-term recursion relations by means of the single expression

$$
\begin{aligned}
& {\left[\begin{array}{llll}
B_{11} & B_{12} & B_{13} & B_{14} \\
B_{21} & B_{22} & B_{23} & B_{24} \\
B_{31} & B_{32} & B_{33} & B_{34} \\
B_{41} & B_{42} & B_{43} & B_{44}
\end{array}\right]=-\left[\begin{array}{llll}
B_{12} & B_{13} & B_{14} & B_{41} \\
B_{11} & B_{42} & B_{43} & B_{44}
\end{array}\right]^{\frac{1}{2}}\left[\begin{array}{cccc}
B_{11}-1 & B_{12}-1 & B_{13}-1 & B_{14}-1 \\
B_{21} & B_{22} & B_{23} & B_{24} \\
B_{31} & B_{32} & B_{33} & B_{34} \\
B_{41}-1 & B_{42-1} & B_{43-1} & B_{44}-1
\end{array}\right]} \\
& -\left[\frac{\left(B_{11}+B_{41}\right)^{2} B_{21} B_{31}}{B_{11} B_{42} B_{43} B_{44}}\right]^{\frac{1}{2}}\left[\begin{array}{cccc}
B_{11-1} & B_{12} & B_{13} & B_{14} \\
B_{21}-1 & B_{22} & B_{23} & B_{24} \\
B_{31}-1 & B_{32} & B_{33} & B_{34} \\
B_{41} & B_{42}-1 & B_{43}-1 & B_{44}-1
\end{array}\right] \text {, }
\end{aligned}
$$

which may be verified with Eq. 3 .

In terms of Wigner's 6-j symbols, Eq. 4 becomes 
$(a+b+d+e+2)[(a-e+f+1)(b-d+f+1)]^{\frac{1}{2}}\left\{\begin{array}{lll}a & b & c \\ d & e & f\end{array}\right\}$
$+[(a+e-f)(b+d-f)(-c+d+e)(c+d+e+1)]^{\frac{2}{2}}\left\{\begin{array}{ccc}a & b & c \\ d-\frac{1}{2} & e-\frac{1}{2} & f+\frac{1}{2}\end{array}\right\}$
$+[(a+b-c+1)(b+d+f+2)(a+e+f+2)(a+b+c+2)]^{\frac{1}{2}}\left\{\begin{array}{ccc}a+\frac{1}{2} & b+\frac{1}{2} & c \\ a & e & f+\frac{1}{2}\end{array}\right\}=0$.

(4a)

By combining sets of two equations of the type given in Eq. 4 it is possible to obtain only four independent relations which are not related through the symmetry properties. Examples of the four relations are

$$
\begin{aligned}
& {[(-c+d+\theta)(a-e+f+1)(b-d+f+1)(c+d+e+1)]^{\frac{1}{2}}\left\{\begin{array}{lll}
a & b & c \\
d & e & f
\end{array}\right\}} \\
& +\left[\frac{(-c+d+e)(c+d+c+1)-(a+b-c+1)(a+b+c+2)}{(a+b+d+e+2)}\right][(a+e-f)(b+d+f)]^{\frac{2}{2}}\left\{\begin{array}{ccc}
a & b & c \\
d-\frac{1}{2} & e-\frac{1}{2} & f+\frac{1}{2}
\end{array}\right\} \\
& -[(a+b-c+1)(-b+d+f)(-a+c+c)(a+b+c+2)]^{\frac{2}{2}}\left\{\begin{array}{rrr}
a+\frac{1}{2} & b+\frac{1}{2} & c \\
d-\frac{1}{2} & e-\frac{1}{2} & f
\end{array}\right\}=0 \text {, } \\
& (-a+c-d+f)[(a-e+f+1)(c+d+e+1)]^{\frac{1}{2}}\left\{\begin{array}{lll}
a & b & c \\
d & e & f
\end{array}\right\} \\
& +[(b-d+f+1)(a+e-f)(b+d-f)(-c+d+e)]^{\frac{2}{2}}\left\{\begin{array}{ccc}
a & b & c \\
d-\frac{1}{2} & e-\frac{1}{2} & f+\frac{1}{2}
\end{array}\right\} \\
& -[(a+b-c+1)(-a+b+c)(c-d+c)(-a+c+r)]^{\frac{2}{2}}\left\{\begin{array}{ccc}
a+\frac{1}{2} & b & c-\frac{1}{2} \\
a & e-\frac{1}{2} & f
\end{array}\right\}=0
\end{aligned}
$$




$$
\begin{aligned}
& {\left[\frac{(a+b-c)(a+b+c+1)-(-c+d+e)(c+d+e+1)}{(a+b+d+e+1)}\right][(b+d+f+1)(a+e+f+1)]^{\frac{1}{2}}\left\{\begin{array}{lll}
a & b & c \\
d & e & f
\end{array}\right\}} \\
& +[(a-e+f)(b-d+f)(a+b-c)(a+b+c+1)]^{\frac{1}{2}}\left\{\begin{array}{ccc}
a-\frac{1}{2} & b-\frac{1}{2} & c \\
d & e & f-\frac{1}{2}
\end{array}\right\} \\
& -[(-a+e+f)(-b+d+f)(-c+d+e)(c+d+e+1)]^{\frac{1}{2}}\left\{\begin{array}{ccc}
a & b & c \\
d-\frac{1}{2} & e-\frac{1}{2} & f-\frac{1}{2}
\end{array}\right\}=0
\end{aligned}
$$

and

$$
\begin{aligned}
& (a-c+d-f)[(c+d+e+1)(b+d+f+1)(a+f+1)(a+b+c+1)]^{\frac{1}{2}}\left\{\begin{array}{lll}
a & b & c \\
d & e & f
\end{array}\right\} \\
& (b+c+e+f+1)[(a+b-c)(a+e-f)(b+d-f)(-c+d+e)]^{\frac{2}{2}}\left\{\begin{array}{lll}
a-\frac{1}{2} & b-\frac{1}{2} & c \\
d-\frac{1}{2} & e-\frac{1}{2} & f
\end{array}\right\} \\
& -(a+b+d+e+1)[(b-d+f)(c-d+e)(-a+b+c)(-a+e+f)]^{\frac{1}{2}}\left\{\begin{array}{lll}
a & b-\frac{1}{2} & c-\frac{1}{2} \\
d & e-\frac{1}{2} & f-\frac{1}{2}
\end{array}\right\}=0 .
\end{aligned}
$$

With the equations that have been presented it is possible to deduce some simplified expressions for the $6-j$ symbols in special cases in a manner similar to that described previously for the $3-j$ symbols. ${ }^{5}$ It should be noted, for example, that the sum given in Eq. $3 a$ is always an integer or zero since each term in the sum is an integer. Hence, when $B_{11}=0$, the summation index can only assume the value zero and the sum is equal to unity. This fact leads to the simplified expression

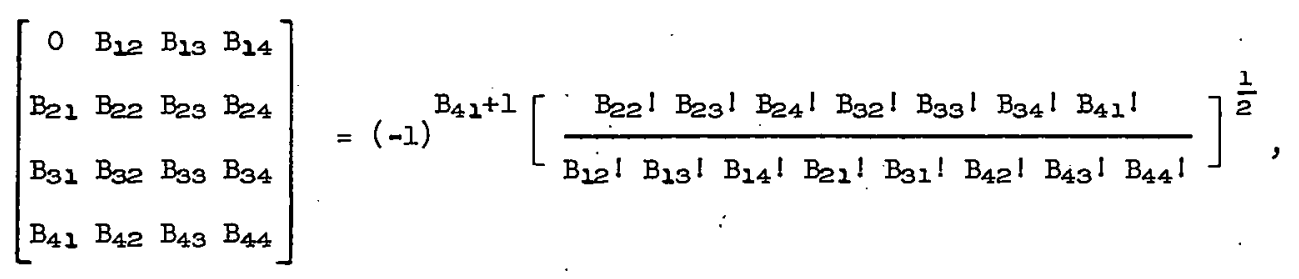

5. C. D. Zerby and R. R. Coveyou, Some Simplified Expressions for the 3-j Symbols, ORNL-TM-514 (to be published). 
which applies to the case in which any $B_{i j}$ for $i \leq 3$ is equal to zero since that element can be transposed to the $B_{11}$ position using the symmetry properties. Thus a simplified equation for the $6-j$ symbol is obtain whenever $j_{k}=j_{l}+j_{m}$ in any set of quantum numbers that form a triangle relation in the 6-j symbol.

If the minimum of the $B_{i j}$ is greater than zero, then a form of the recursion relation given in Eq. 4 can be used to relate the symbol to symbols with the value of the element reduced by one. In this way the symbol can finally be reduced to the form given in Eq. 6. Alternatively, the element with the minimum value can be transposed to the $B_{11}$ position and Eq. 4 can be used in the form it is presented. In the latter case there is an advantage to using the recursion relation for the symbol defined in Eq. 3a since it is always an integer. The substitution of Eq. 3 into Eq. 4 yields

$$
\begin{aligned}
& \left\{\begin{array}{llll}
B_{11} & B_{12} & B_{13} & B_{14} \\
B_{21} & B_{22} & B_{23} & B_{24} \\
B_{31} & B_{32} & B_{33} & B_{34} \\
B_{41} & B_{42} & B_{43} & B_{44}
\end{array}\right\}=\left[\begin{array}{lll}
B_{12} & B_{13} & B_{14}
\end{array}\right]\left\{\begin{array}{cccc}
B_{11}-1 & B_{12}-1 & B_{13}-1 & B_{14}-1 \\
B_{21} & B_{22} & B_{23} & B_{24} \\
B_{31} & B_{32} & B_{33} & B_{34} \\
B_{41-1} & B_{42}-1 & B_{43-1} & B_{44}-1
\end{array}\right\} \\
& -\left[B_{21} B_{31}\left(B_{11}+B_{41}\right)\right]\left\{\begin{array}{cccc}
B_{11}-1 & B_{12} & B_{13} & B_{14} \\
B_{21}-1 & B_{22} & B_{23} & B_{24} \\
B_{31}-1 & B_{32} & B_{33} & B_{34} \\
B_{41} & B_{42}-1 & B_{43}-1 & B_{44}-1
\end{array}\right\} \cdot(7)
\end{aligned}
$$

From Eqs. 3 and 7 and the fact that the symbol with braces is equal to unity when the element in the $B_{11}$ position is equal to zero, one can quickly deduce that 


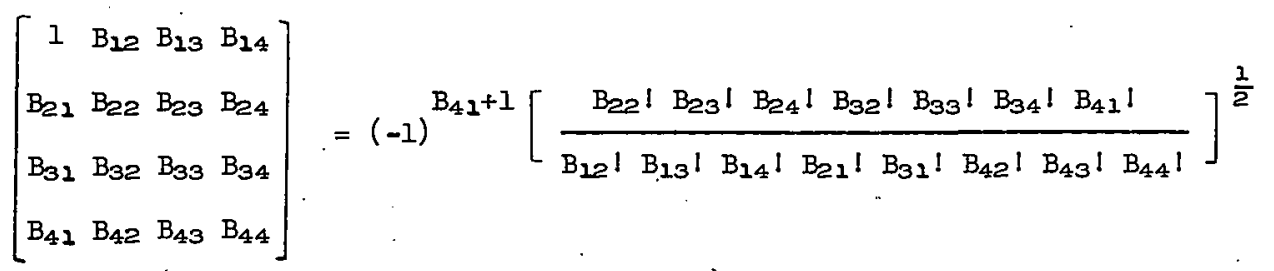

$$
\begin{aligned}
& X \quad\left\{\left[\begin{array}{lll}
B_{12} & B_{13} & B_{14}
\end{array}\right] \div\left[\begin{array}{lll}
B_{21} & B_{31} & \left(B_{41}+1\right)
\end{array}\right]\right\}
\end{aligned}
$$

$$
\begin{aligned}
& {\left[\begin{array}{cccc}
2 & B_{12} & B_{13} & B_{14} \\
B_{21} & B_{22} & B_{23} & B_{24} \\
B_{31} & B_{32} & B_{33} & B_{34} \\
B_{41} & B_{42} & B_{43} & B_{44}
\end{array}\right]=(u 1)^{B_{41}+1}\left[\frac{B_{22} ! B_{23} ! B_{24} ! B_{32} ! B_{33} ! B_{34} ! B_{41} !}{2 B_{12} ! B_{13} ! B_{14} ! B_{21} ! B_{31} ! B_{42} ! B_{43} ! B_{44} !}\right]^{\frac{1}{2}}} \\
& X\left\{\left[B_{12} B_{13} B_{14}\right]\left\{\left(B_{12}-1\right)\left(B_{13}-1\right)\left(B_{14}-1\right)-B_{21} B_{31} B_{11}\right\}\right. \\
& \left.-\left[B_{21} B_{31}\left(B_{41}+2\right)\right]\left\{B_{12} B_{13} B_{14}-\left[\left(B_{21-1}\right)\left(B_{31}-1\right)\left(B_{41}+1\right)\right]\right\}\right\}
\end{aligned}
$$

etc. Equation 8 provides expressions for the symbols when $j_{k}=j_{l}+j_{m}-1$ in any of the four triangle relations and Eq. 9 provides: similar expressiuns fur $j_{k} \equiv j_{\ell}+j_{m}-2$. 


\author{
ORNL-3440 \\ UC-34 - Physics \\ TID-4500 (19th ed., Rev.)
}

\title{
INTERNAL DISTRIBUTION
}

1. Biology Library

2-3. Central Research Library

4. Reactor Division Library

5-6. ORNL - Y-12 Technical Library Document Reference Section

7-56. Laboratory Records Department 57. Laboratory Recurds, ORNL R.C. 58. Donald Arnurius

59. J. B. Ball

60. E. P. Blizard

61. Brian Buck

62. J. L. Clark (K-25)

63. J. W. T. Dabbs

64. C. D. Goodman

65. A. A. Grau

66. W. H. Jordan

67. H. W. Joy

68. M. Kastenbaum
69. T. S. Kress

70. C. E. Larson

71. M. E. LaVerne

72. R. V. Miskell

73. S. K. Penny

74. C. W. Nestor, Jr.

75. Frances Perey

76. R. H. Ritchie

77. H. C. Schweinler

78. M. J. Skinner

79. J. A. Swartout

80. A. M. Weinberg

81-85. C. D. Zerby

86. R. A. Charpie (consultant)

87. P. F. Gast (consultant)

88. R. F. Taschek (consultant)

89. T. J. Thompson (consultant)

EXIERNAL DISTRIBUTION

90. Research and Development Division, AEC, ORO

91-727. Given distribution as shown in TID-4500 (19th ed., Rev.) under Physics category ( 75 copies - OTS) 